\title{
Comparison of Numerical Weather Prediction Based Deterministic and Probabilistic Wind Resource Assessment Methods
}

\author{
Jie Zhang ${ }^{\mathrm{a}}$, Caroline Draxl ${ }^{\mathrm{a}}$, Thomas Hopson ${ }^{\mathrm{b}}$, Luca Delle Monache ${ }^{\mathrm{b}}$, \\ Emilie Vanvyve ${ }^{\mathrm{b}, \mathrm{c}}$, Bri-Mathias Hodge ${ }^{\mathrm{a}, *}$ \\ ${ }^{a}$ National Renewable Energy Laboratory, Golden, CO 80401, USA \\ ${ }^{b}$ National Center for Atmospheric Research, Boulder, CO 80307, USA \\ ${ }^{c}$ Met Office, Exeter, EX1 3PB, United Kingdom
}

\begin{abstract}
Numerical weather prediction (NWP) models have been widely used for wind resource assessment. Model runs with higher spatial resolution are generally more accurate, yet extremely computational expensive. An alternative approach is to use data generated by a low resolution NWP model, in conjunction with statistical methods. In order to analyze the accuracy and computational efficiency of different types of NWP-based wind resource assessment methods, this paper performs a comparison of three deterministic and probabilistic NWP-based wind resource assessment methodologies: (i) a coarse resolution $\left(0.5^{\circ} \times 0.67^{\circ}\right)$ global reanalysis data set, the Modern-Era Retrospective Analysis for Research and Applications (MERRA); (ii) an analog ensemble methodology based on the MERRA, which provides both deterministic and probabilistic predictions; and (iii) a fine resolution (2-km) NWP data set, the Wind Integration National Dataset (WIND) Toolkit, based on the Weather Research and Forecasting model. Results show that: (i) As expected, the analog ensemble and WIND Toolkit perform significantly better than MERRA confirming their ability to downscale coarse estimates; (ii) The analog ensemble provides the best estimate of the multi-year wind distribution at seven of the nine sites available, while the WIND Toolkit is the best at one site; and (iii) the WIND Toolkit was more accurate in estimating the distribution of hourly wind speed differences which characterize the wind variability at five of the available sites, with the analog ensemble being best at the remaining four locations; (iv) the analog ensemble computational cost is negligible, whereas the WIND Toolkit requires large computational resources. Future efforts could focus on the combination of the analog ensemble with intermediate resolution (e.g., 10-15 km) NWP estimates, to considerably reduce the computational burden, while providing accurate deterministic estimates and reliable probabilistic assessments.
\end{abstract}

Keywords: analog ensemble, numerical weather prediction, probabilistic wind resource assessment, variability, WIND Toolkit, MERRA

\section{Introduction}

Renewable energy resources, particularly wind energy, have become a primary focus in government policies, in academic research, and in the power industry. During the past decade, notable progress has been made in promoting renewable energy resources; among them, wind energy has taken the lead, and currently contributes approximately $4 \%$ of worldwide electricity consumption [1]. However, there are still many challenges at different stages of a wind energy project. For example, the available energy from the wind resource varies appreciably during a year. In addition, wind power generation differs from conventional power generation because of the variable and uncertain nature of the wind, which can have significant impacts on grid operations. Therefore, it is very important to accurately estimate the wind conditions, and evaluate the uncertainty in the wind resource and energy production at a potential wind plant site. This is often done using numerical weather prediction (NWP) models. This paper investigates different numerical weather prediction based methodologies for wind resource applications. 


\subsection{Overview of Wind Resource Assessment}

Wind resource assessment is the process of estimating the power potential of a wind plant site, which plays an important role in a wind energy project. A comprehensive wind resource assessment usually entails the following tasks [2-4]:

1) Site prospecting: identification of a suitable site using cartography (e.g., wind maps, political maps, etc.).

2) Measurement campaign: characterization of the on-site wind resource by recording the winds for 1 to 4 years as close as possible to hub height, with temporary meteorological masts (possibly completed or supplemented with remote sensing instruments).

3) Microscale vertical extrapolation: transfer of the measurements to hub heights.

4) Long-term extrapolation: extension of the measurements to the 10- to 30-year-long operation lifetime using historical observations (e.g., nearby tall towers, surface weather stations, rawinsonde stations, and modeled data sets such as reanalyses) and (mostly) statistical methods.

5) Wind farm layout design: establishment of turbine locations relative to wind resource estimation (e.g., using standard wake models or computational fluid dynamic models).

6) Gross energy production estimation: calculation of the potential wind energy production over a year (or over the lifetime) for the whole site.

7) Energy losses assessment: evaluation of losses due to various causes (e.g., equipment downtime, array losses, etc.).

8) Uncertainty estimation: careful evaluation of the uncertainty associated with every step above. Physical uncertainties in wind energy may be broadly classified into long-term and short-term uncertainties. Longterm uncertainties are mainly introduced by (i) variation of wind conditions, (ii) turbine design, and (iii) other environmental, operational and financial factors. Short-term uncertainties are mainly introduced by boundary layer turbulence and other flow variations that occur over small time scales (order of minutes).

Evaluating and reducing the uncertainties are of particular importance to secure financing and ensuring the investor's confidence. The uncertainties drive the probability distribution of the expected energy production. A recent comparison of pre-construction energy assessments for about 200 North American utility-scale wind farms to the actual power output highlighted the breakdown of contributions to the total energy production uncertainty (Fig. 1) [5]. These values depend on many factors, including the project size, the topography complexity, and the availability of historical wind data.

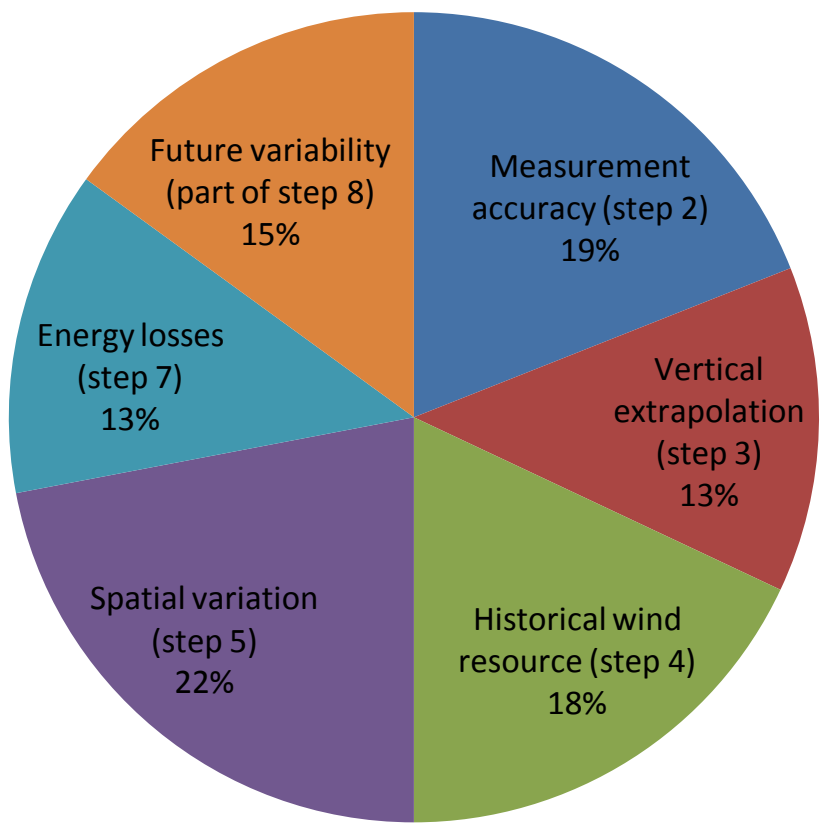

Figure 1. Breakdown of contributions to the total energy production uncertainty [5].

This paper focuses on the long-term extrapolation of wind conditions (step 4). Measure-correlate-predict (MCP) methods are widely used to assess the long-term wind resource at target sites using short-term (one- or two-year) on-site data and concurrent data at nearby weather stations [6-9]. Wind measurements from weather 
stations have limitations, such as wind measurements being available at standard levels only, missing data, instrumentation errors, etc. Data generated by NWP models has been widely used for wind resource assessment [10-12]. NWP models are based on conservation equations (of momentum, energy, and mass) to simulate the physical interactions in the atmosphere. A number of NWP models are available worldwide covering different domains and with different resolutions, e.g., the Modern-Era Retrospective Analysis for Research and Applications (MERRA) model, the Weather Research and Forecasting (WRF) model, the European Centre for Medium-Range Weather Forecasts (ECMWF), the High-Resolution Rapid Refresh (HRRR) model, etc. [10].

\subsection{Literature overview}

Several wind resource assessment and wind power integration studies based on NWP models can be found in the literature. Al-Yahyai et al. [10] reviewed and discussed the advantages and limitations of using NWP models for wind resource assessment. Jimenez et al. [11] compared two different NWP approaches, the mesoscale meteorological model MM5 and the wind resource assessment program WAsP (Wind Atlas Analysis and Application Program), to assess the offshore wind resource over the German Bight in the North Sea. Chagas et al. [12] used the WRF model for wind resource assessment and showed that their modeled wind speed is generally 5\% lower than the measured data. Cassola and Burlando [13] applied Kalman filters to the NWP output, showing that the method is capable to provide significant forecast improvement, especially when used for very short-term forecast. Alessandrini et al. [14] compared two different ensemble methods for short-term wind power forecasting based on real data, the Ensemble Prediction System (EPS) in use at the European Centre for Medium-Range Weather Forecasts (ECMWF) and the Limited-area Ensemble Prediction System (LEPS) developed within COnsortium for Small-scale MOdelling (COSMO). Carvalho et al. [15, 16] analyzed the sensitivity of NWP models for both wind simulation and wind energy production estimates, by comparing the different NWP model configurations. The National Renewable Energy Laboratory has created U.S. wind resource maps based on outputs of NWP models [17]. Both wind and solar data sets were created through NWP models for U.S. large scale grid integration studies, such as the Western Wind and Solar Integration Study [18, 19] and the Eastern Wind Integration and Transmission Study [20]. Vanvyve et al. [22] proposed for the first time an analog-based method for wind resource estimates, as described in details below.

\subsection{Research Motivation and Objectives}

The integration of wind energy into the power system is becoming more challenging with the increased penetration of wind power. Wind power generation is driven by the variation of the wind over many different timescales; therefore, it is essential to have a clear understanding of both the wind and the turbine performance at spatial and temporal resolutions that are important for balancing authorities and utilities. This need in turn implies high-resolution data (e.g., $2 \mathrm{~km}$ ) covering large regions and periods from a few minutes to several years. However, higher spatial resolution results in more accurate model output and higher computational expense. For wind resource assessment, wind data over a 10- or 20-year period are required. A high resolution NWP model may take several months to produce the data. An alternative way is to use data generated by a low resolution NWP model, in conjunction with statistical methods. It is important to understand the strengths and weaknesses of the two approaches, from the perspective of wind resource assessment and wind power integration.

In this paper, we performed a comparison of three deterministic and probabilistic wind resource assessments based on NWP models: (i) a low resolution reanalysis data set, the Modern-Era Retrospective Analysis for Research and Applications (MERRA) [21]; (ii) an analog ensemble methodology based on the MERRA model and on-site observations, which provides both deterministic and probabilistic predictions [22]; and (iii) a high resolution NWP data set, the Wind Integration National Dataset (WIND) Toolkit based on WRF model [23, 24]. The remainder of the paper is organized as follows: the three NWP-based methods are presented in Section 2. The selection of test sites and a description of the data are provided in Section 3. Section 4 presents the performance evaluation metrics used for the results shown in Section 5; and a discussion in Section 6 is followed by the conclusions in Section 7.

\section{NWP Based Methods for Wind Resource Assessment}

\subsection{Low Resolution NWP: Modern-Era Retrospective Analysis for Research and Applications (MERRA)}

The National Aeronautics and Space Administration (NASA) MERRA data set is a freely available and highquality global reanalysis of weather occurring since 1979, which was built from the Goddard Earth Observing System version 5 Data Assimilation System (GEOS-5 DAS) [21]. With a $0.5^{\circ}$ x $0.67^{\circ}$ horizontal resolution, there are 72 vertical levels in the GEOS-5 DAS, which extends through the stratosphere with data assimilation 
occurring over a range of these levels. GEOS-5 DAS assimilates observations from many sources: radiosondes, wind profilers, aircrafts, ships, buoys, radars, land surface stations, and virtually every existing major satellite dataset. MERRA is one of the few global atmospheric reanalyses that use data from the entire constellation of NASA earth observing system satellites. The MERRA dataset has been publicly available online since 2008 and is kept up-to-date (with only a few months lag), making it particularly suitable for wind resource assessment applications. For this study, 1-hour interval output was used over the chosen period. To derive the wind data at the final spatial location, bilinear interpolation to the station point locations was applied to the MERRA datasets.

The MERRA data are those at the lowest model level available. For the studied sites in the paper, this corresponds to approximately $63 \mathrm{~m}$ above ground level. One advantage of using the lowest model level over higher level is that data is hourly instead of 6-hourly. A power law approximation is adopted to approximate the model levels to the desired fixed height of the observation.

\subsection{Analog Ensemble Methods based on Low Resolution NWP}

The accuracy of MERRA predictions is limited by its low resolution. Instead of directly using MERRA data for wind resource assessment, statistical methods can be applied by correlating the long term available MERRA data with the short term observed wind data at the wind site. To that end, an analog ensemble method was adopted in this paper, which can provide both probabilistic and deterministic estimates of the long-term wind speed. It is important to note that the analog ensemble method was applied to the lowest model level MERRA data (without any power law approximation).

\subsubsection{Analog Ensemble Derived Methodology}

Analog ensemble (AnEn) techniques have been used with success for short-term weather and hydrologic predictions [25-30]. In the context of the wind resource assessment [22], following Delle Monache et al. [28], the AnEn method draws on the information contained in a long-term reanalysis (known as historical data) of multiple physical quantities that are related to available targeted wind speed observations (known as the predictand) collected over a short time period (known as the training period, typically 365 days). The relationships derived within the training period are then applied to reconstruct the wind speed at the target site over the period for which there are no observations (hereafter referred to as reconstructed period, e.g., the past 20 years before the measurement campaign started).

More precisely, AnEn is a three-stage process that is executed independently at every target site and for every hour $t$ of the reconstructed period, as sketched in Fig. 2:

1) The historical value of multiple physical quantities (known as analog predictors, e.g., wind speed, wind direction, pressure, etc.) are retrieved for a time window (known as an analog trend) centered around time $t$ (red star in Fig. 2). The analog predictors are selected beforehand based on their known or anticipated correlations to the predictand.

2) Other historical cases over the training period with conditions analog to those in the target window are identified (red marks in top series of Fig. 2) by looking at a time window (known as analog search window) centered around the same hour of the day for every day in the training period, and ranked by closeness of match (as estimated with Eq. 1). Analogs may therefore come from any day, week or month of the training period. Using multiple predictors helps distinguish the analogs by identifying specific weather regimes relevant to the predictand.

3 ) The $K$ best analog cases ( $K$ being the number of analogs) are selected, and the corresponding observed values of the predictand are retrieved (red dots in bottom series of Fig. 2). The latter constitute the analog ensemble members for the given time $t$, that are used to estimate the distribution of the likely values of the reconstructed time series as denoted by the box and whiskers of Fig. 2.

The final result is the analog ensemble, i.e., a set of $K$ wind speed values for every hour $t$ of the reconstructed period. The assumption is that if analogs are found, their errors will likely be similar to the error of the historical time step that they match (red star in Fig. 2), and the error of the latter can be inferred from the errors of the analogs. Therefore, the analog ensemble members yield two types of information: (i) a deterministic wind speed estimate when the members are combined to produce a single representative value (e.g., weighted average, see Section 2.2.2), and (ii) an estimate of uncertainty through the probabilistic distribution of wind speed provided by the analog ensemble. In other words, the range of the analog ensemble contains information about the likelihood of occurrence of the deterministic value. We use 25 ensemble members for this study.

In the present study, no attempt was made to find optimal parameters for all predictors, although recently Junk et al. [31] have demonstrated that the analog ensemble performance can be significantly improved by choosing optimal predictors weights. 


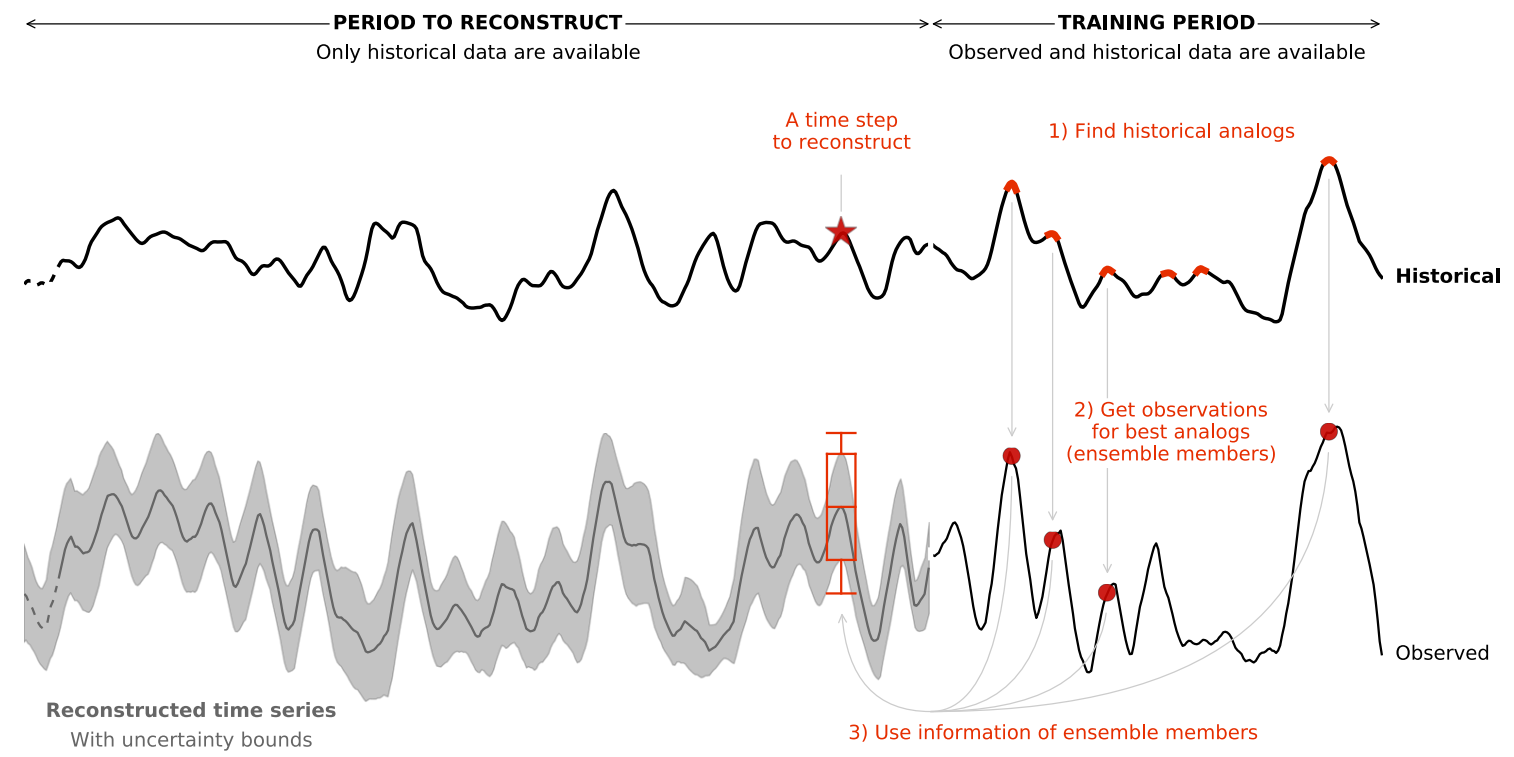

Figure 2. Sketch of the functioning of the analog ensemble method; the functioning is illustrated here for one analog predictor, an analog trend reduced to one time step, and when retaining the best four analogs (reprinted from Ref. [22]).

\subsubsection{Reconstructing Temporal Autocovariance - Schaake Shuffle Ensemble (SSEn)}

Often, after constructing ensemble estimates of a variable over a range of time steps, it is desired to reconstruct individual (deterministic) time series out of the sequence of ensembles such that the temporal autocovariance resembles that which one would expect from the observed time series for that same variable. The reasons for this reconstruction could be varied, but one typical application would be for scenario generation for another coupled variable (e.g., ensembles of possible wind speed converted to expected ranges of power generation). One technique used in the literature to this end is the Schaake Shuffle (SSEn) [32].

In SSEn, the ensemble output is simply reordered to recover the temporal variability in the weather variable (i.e., wind speed here). The ensemble members for a given estimation (or forecast) time are ranked and matched with the rank of the weather variable data from time windows (e.g., days) randomly selected from similar dates in the historical record, such that each date corresponds to one of the ensemble members. To create autocorrelation for the next time step, the matched dates are moved forward one day, and the new reordering of the observed data is imposed on the order of the matched ensembles for this next time step. This process then continues time-step by time-step over the whole length of the time interval desired. Using this approach, the observed temporal persistence is almost entirely recovered. More details on SSEn can be found in Ref. [32].

As it will be shown in the next sections, SSEn preserves the characteristics of the analog ensemble distribution, and therefore while it provides a set of consistent deterministic time series, it can also be used to estimate effectively the observed wind speed distribution, or the observed hourly wind speed differences. In this study, the analog ensemble method was trained using one year of historical data. Table 1 shows the training and prediction periods at the 9 locations (Table 3), which are described in details in section 3 .

Table 1. Training and prediction periods at selected sites

\begin{tabular}{lccc}
\hline \multicolumn{1}{c}{ Station } & Measured height $(\mathrm{m})$ & Training period & $\begin{array}{c}\text { Prediction period } \\
\text { (comparison period) }\end{array}$ \\
\hline Boulder NWTC & 80 & $2012-01-02$ to 2012-12-31 & $2009-01-02$ to 2012-01-01 \\
Bovina 100 & 100 & $2011-03-03$ to 2012-03-01 & $2010-03-03$ to 2011-03-02 \\
Bovina 50 & 50 & $2011-10-10$ to 2012-10-08 & $2010-10-10$ to 2011-10-09 \\
Cape May & 100 & $2008-09-25$ to 2009-09-24 & $2007-09-26$ to 2008-09-24 \\
Cedar Creek A09 & 80 & $2012-01-02$ to 2012-12-31 & $2009-01-02$ to 2012-01-01 \\
Cedar Creek H06 & 69 & $2011-01-02$ to 2012-12-31 & $2009-01-02$ to 2011-01-01 \\
Cochran & 70 & $2011-06-30$ to 2012-06-28 & $2008-06-30$ to 2011-06-29 \\
Goodnoe Hills & 59.4 & $2009-01-01$ to 2009-12-31 & $2007-01-01$ to 2008-12-31 \\
Megler & 53.3 & $2011-11-03$ to 2012-11-01 & $2010-11-03$ to 2011-11-02 \\
\hline
\end{tabular}

\subsection{High Resolution NWP: The Wind Integration National Dataset (WIND) Toolkit}

The WIND Toolkit includes meteorological conditions and turbine power for 126,692 sites in the continental United States for the years 2007-2013 (Fig. 3). The WIND Toolkit was produced with the Weather Research and Forecasting (WRF) model [33] version 3.4.1. The meteorological data set has $2 \times 2 \mathrm{~km}$ horizontal resolution, 9 vertical levels, a temporal resolution of 5 minutes, and covers a 7-year period (2007-2013). The simulations 
include a spin-up period of 48 hours. The model was restarted every month, and we used scale selective grid nudging. There are three main data sets included in the WIND Toolkit [23, 24]:

1) The meteorological data set includes basic information on the weather conditions in each $2 \times 2 \mathrm{~km}$ grid cell, e.g., wind profiles, atmospheric stability, and solar radiation data.

2) A power data set was created using the wind data and site-appropriate turbine power curves to estimate the power produced at each of the turbine sites.

3) A forecast data set includes forecasts for 1-hour, 4-hour, 6-hour, and 24-hour forecast horizons.

The WIND Toolkit has been funded by the U.S. Department of Energy, Office of Energy Efficiency and Renewable Energy, Wind and Water Power Technologies Office and was created through the collaborative efforts of the National Renewable Energy Laboratory (NREL) and 3Tier (http://maps.nrel.gov/wind_prospector). More details of the WIND Toolkit can be found in Ref. [34]

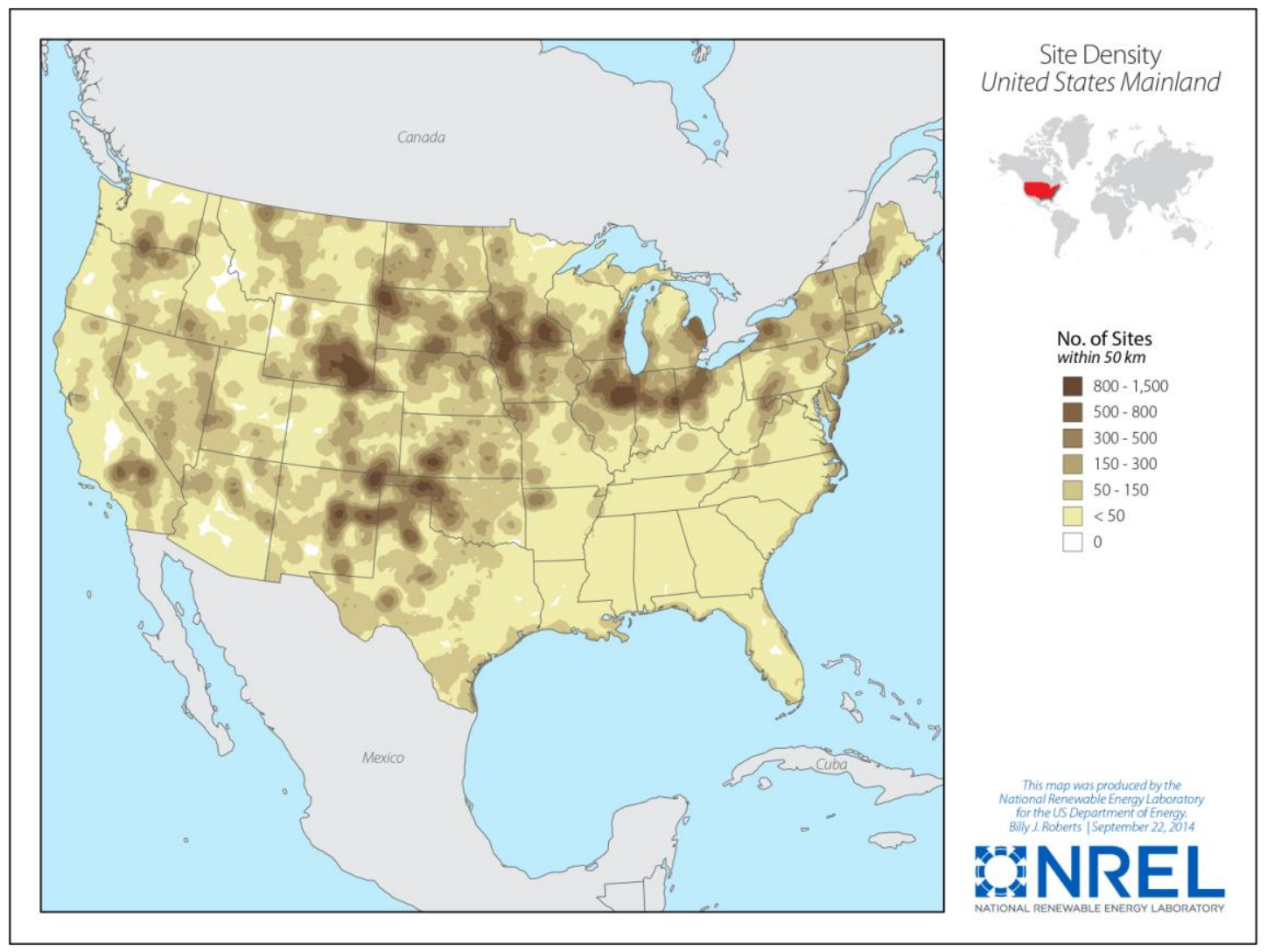

Figure 3. Map showing the site density of the 126,692 wind sites [23]

\section{Sites Selection and Data Summary}

The comparison of three NWP-based wind resource assessment methods (MERRA, AnEn based on MERRA, and WIND Toolkit) was performed with measurements at 9 locations across the United States. Tall tower data at these 9 locations were chosen with the following criteria:

1) The locations should represent different topographies and climates.

2) Observed wind speed and direction values should be available at $50 \mathrm{~m}$ or higher for at least two years.

3) One site should include measurements at different heights.

4) A variety of time periods should be represented.

5) At least one site should be in close proximity (i.e., not more than $40 \mathrm{~km}$ apart) to another site to analyze the methods for adjacent sites.

6) The measurement data should require minimal additional quality control.

7) One of the sites should be a wind farm for potential future power analyses.

Table 2 summarizes the site information of the measurements, including station names, date ranges, years available to process, issues associated with the data, and fulfilled selection criteria. Figure 4 provides postage stamp snapshots of the wind stations used in this study, showing the wide range of geographical location and topographic variability encompassed in this study, following the criteria above. 


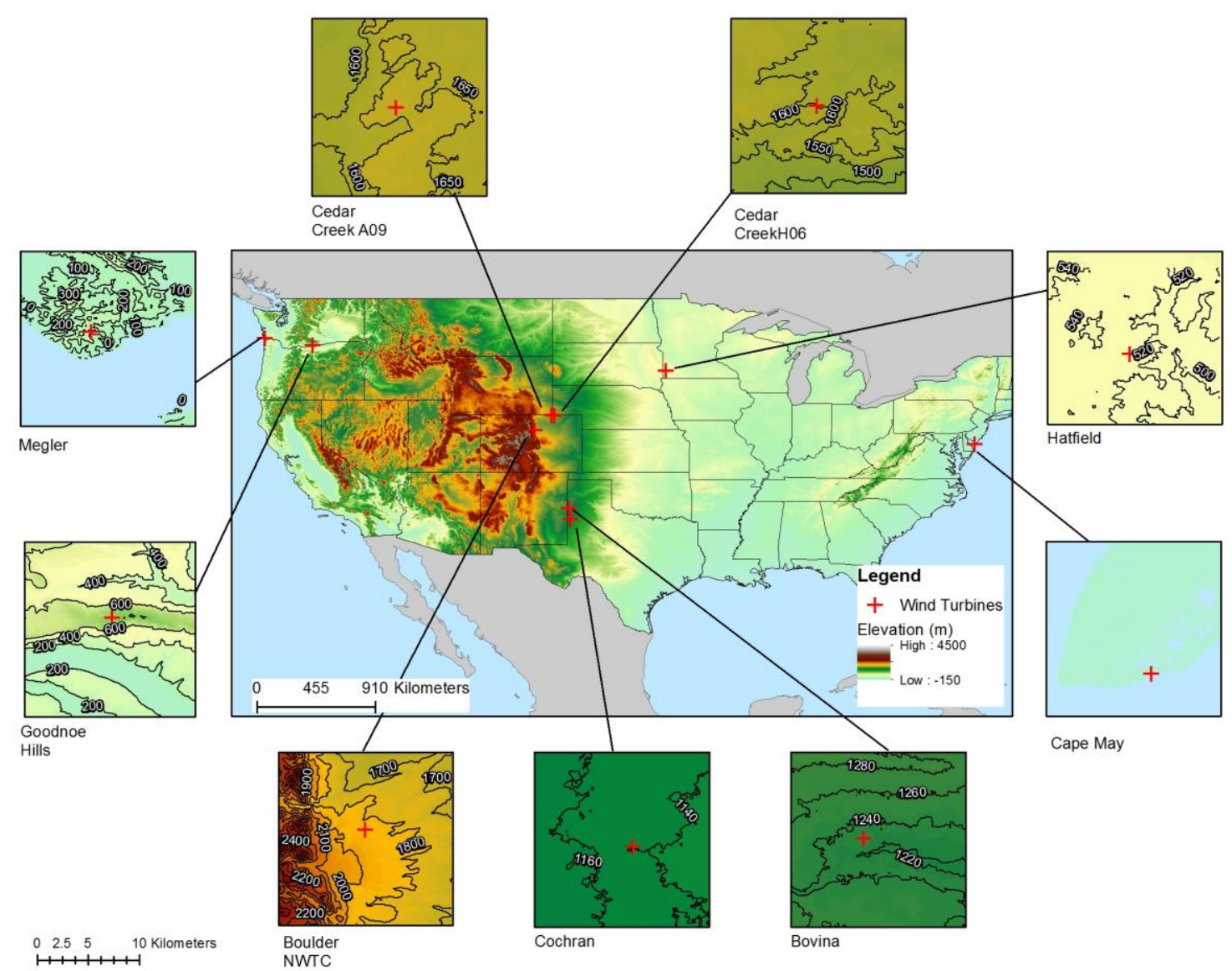

Figure 4. The geographical locations of the 9 wind site stations, showing the wide range of geographical locations and topographical variability. (Note that Bovina site is actually composed of two stations at two heights: $50 \mathrm{~m}$ and $100 \mathrm{~m}$ ).

Each observed data set was quality controlled with the software Windographer [35]. Following data were removed: (i) outliers, (ii) the data from icing periods when the temperature was below $5^{\circ} \mathrm{C}$, (iii) the wind speed was below $0.5 \mathrm{~m} / \mathrm{s}$, and (iv) the direction change within $40 \mathrm{~min}$ was less than 1 degree. General outages were defined as wind speed changes of less than $0.1 \mathrm{~m} / \mathrm{s}$ within 1 hour and removed. For a comparison with the analog ensemble technique, the observations, mostly 10-min averages, were averaged to hourly values at the half hour to be consistent with the MERRA data. For a comparison with the WIND toolkit data, the hourly averaged observed wind speeds were used.

\begin{tabular}{lccc}
\multicolumn{4}{c}{ Table 2. Data summary at the 9 selected sites } \\
\hline \multicolumn{1}{c}{ Station } & Dates available & Years of data & Selection criteria \\
\hline Boulder NWTC & $1996-09-24$ to 2013-05-20 & $>5$ & Complex terrain \\
Bovina 100 m & $2009-06-17$ to 2011-12-31 & 2 & Multiple heights, flat terrain \\
Bovina 50 m & $2009-06-17$ to 2012-10-08 & 2 & Multiple heights, flat terrain \\
Cape May & $2007-09-25$ to 2009-12-14 & 2 & East coast \\
Cedar Creek A09 & $2008-10-23$ to 2013-05-13 & 4 & Power data available \\
Cedar Creek H06 & $2008-10-23$ to 2013-05-11 & 4 & Power data available \\
Cochran & $2008-03-01$ to 2012-06-28 & 4 & Flat terrain, close to Bovina \\
Goodnoe Hills & $2000-01-01$ to 2009-12-31 & $>5$ & Complex terrain \\
Megler & $2010-02-02$ to 2012-11-01 & 2 & West coast \\
\hline
\end{tabular}

\section{Evaluation Methods}

Two sets of performance metrics are proposed to evaluate the three wind resource assessment methods: (i) wind speed metrics, including distribution of wind speed, temporal autocorrelation of wind speed, distribution of wind speed error, and distribution of hourly wind speed difference; and (ii) wind farm performance: power generation of a hypothetical nine-turbine wind farm.

\subsection{Wind Speed Metrics}

Four metrics were adopted to evaluate the performance of the three NWP-based methods concerning wind 
speeds, including (i) the distribution of wind speed; (ii) temporal autocorrelation of wind speed from 1 to 48 hours lags, which characterize the variability of wind speed; (iii) the distribution of wind speed error, which shows the overall accuracy of the wind speed dataset; and (iv) the distribution of hourly differences of the wind speed, which characterizes the variability in wind speed. Variability is one of most important factors affecting the cost of wind integration. The wind speed error $\left(E_{w}\right)$ is calculated by

$$
E_{w}=U_{\mathrm{m}}-U_{a}
$$

where $U_{m}$ is the modelled wind speed from MERRA, SSEn, or WIND Toolkit; $U_{a}$ is the measured wind speed. The hourly difference of wind speed $\left(E_{d}\right)$ is given by

$$
E_{d}=U_{t}-U_{t-1}
$$

where $U_{t}$ is the modelled or measured wind speed at hour $t ; U_{t-1}$ is the corresponding modelled or measured wind speed at hour $t-1$.

The distribution of wind speed (wind speed error, or hourly wind speed differences) is estimated using kernel density estimation (KDE). KDE is a nonparametric approach to estimate the probability density function of a random variable. KDE has been widely used in the renewable energy community for wind speed distribution characterization and wind and solar power forecasting [36-38].

\subsection{Metrics of Wind Power Estimations}

To estimate wind power from wind speeds, a power generation model was adopted from Chowdhury et al. $[39,40]$. The power generated by a wind plant is an intricate function of the configuration and location of the individual wind turbines. The flow pattern inside a wind plant is complex, primarily because of the wake effects and the highly turbulent flow. The power generated by a wind plant $\left(\mathrm{P}_{\text {plant }}\right)$ consisting of $\mathrm{N}$ wind turbines is evaluated as a sum of the powers generated by the individual turbines, which is expressed as

$$
P_{\text {plant }}=\sum_{j=1}^{N} P_{j}
$$

The power generation model (i) uses the wake growth model proposed by Frandsen et al. [41]; (ii) implements the wake superposition model developed by Katic et al. [42]; and (iii) includes the estimated distribution of wind speed and wind direction. The wake velocity immediately behind the turbine is estimated from the induction factor. A variable induction factor, dependent on the turbine power characteristics and the incoming wind velocity, is used [39]. The power generation model accounts for wake merging and partial wake-rotor overlap. The power generated by each turbine is determined using the turbine power curve, which gives the power generated by the turbine as a function of the approaching wind velocity. A newly developed Multivariate and Multimodal Wind Distribution (MMWD) model [36] is used to characterize the distribution of wind speed

\begin{tabular}{|c|c|}
\hline Turbine Feature & 1.5-MW XLE \\
\hline Rated Power & $1.5 \mathrm{MW}$ \\
\hline Rated Wind Speed & $11.5 \mathrm{~m} / \mathrm{s}$ \\
\hline Cut-In Wind Speed & $3.5 \mathrm{~m} / \mathrm{s}$ \\
\hline Cut-Out Wind Speed & $20.0 \mathrm{~m} / \mathrm{s}$ \\
\hline Rotor Diameter & $82.5 \mathrm{~m}$ \\
\hline Hub Height & $80.0 \mathrm{~m}$ \\
\hline
\end{tabular}
and wind direction. The power generated by a wind plant with 9 GE 1.5-MW XLE turbines was evaluated in this paper. The features of the GE 1.5-MW XLE turbine are provided in Table 3.

\section{Results}

The estimated wind speeds from MERRA (low resolution NWP), the analog ensemble based on MERRA, and the WIND Toolkit (high resolution NWP) were compared during the comparison period (Table 1).

\subsection{Comparison at $100 \mathrm{~m}-$ Bovina and Cape May}

Figure 5 shows the comparison results at the Bovina site with $100 \mathrm{~m}$ data. The distribution of wind speed in Fig. 5(a) shows that the SSEn and the WIND Toolkit data match the measured wind speeds more closely than the MERRA data. With respect to the WIND Toolkit, the SSEn members deviate more from the true distribution in the low wind speed region $(0-3 \mathrm{~m} / \mathrm{s})$ but are more accurate in the high wind speed region $(12-18 \mathrm{~m} / \mathrm{s})$. This explains the fatter tails for SSEn in the distributions of wind speed errors (Fig. 5(c)). The WIND Toolkit data 
exhibit the most accurate temporal prediction at this location especially for lags less than 20 hours (see Fig. 5(b), autocorrelation of wind speed), and successfully capture the variability in wind speed (see hourly difference of wind speed in Fig. 5(d)). Figures 5(e) illustrates the distribution of wind power error for a 9-turbine wind plant. It shows that the SSEn members have fatter tails than WIND Toolkit and MERRA, especially for the right tails. In addition, oscillations present in the tails of distributions for all three methods (compared with the distribution of wind speed error), indicating that uncertainty becomes more complex in wind power estimations. This can be attributed to the additional uncertainty in the wind power generation model.

For this site, it is observed that all methods (MERRA, WIND Toolkit, and SSEn) could capture the observed wind variation. Overall, the WIND Toolkit has a relatively better deterministic performance and SSEn has the advantage of also providing probabilistic information of wind resource assessment.

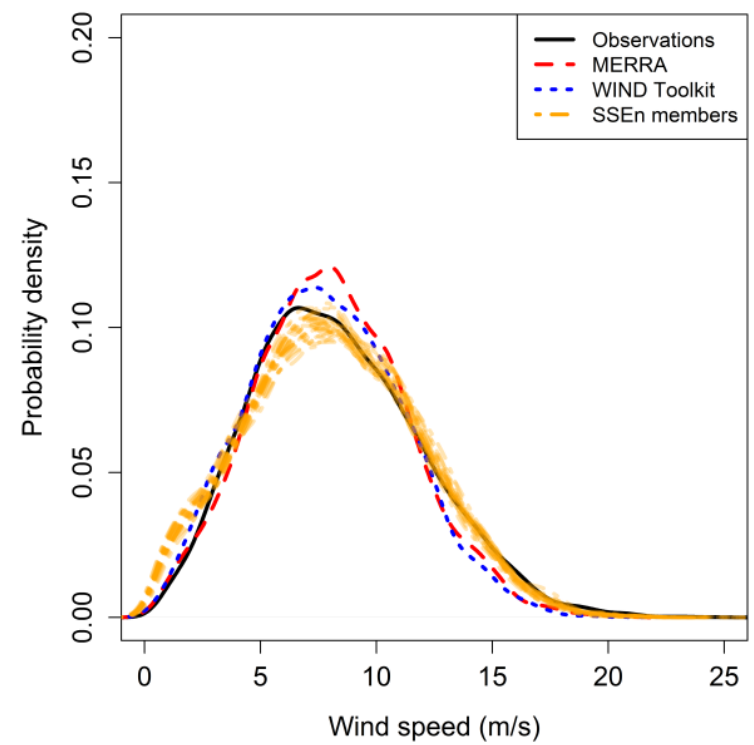

(a) Distribution of wind speed

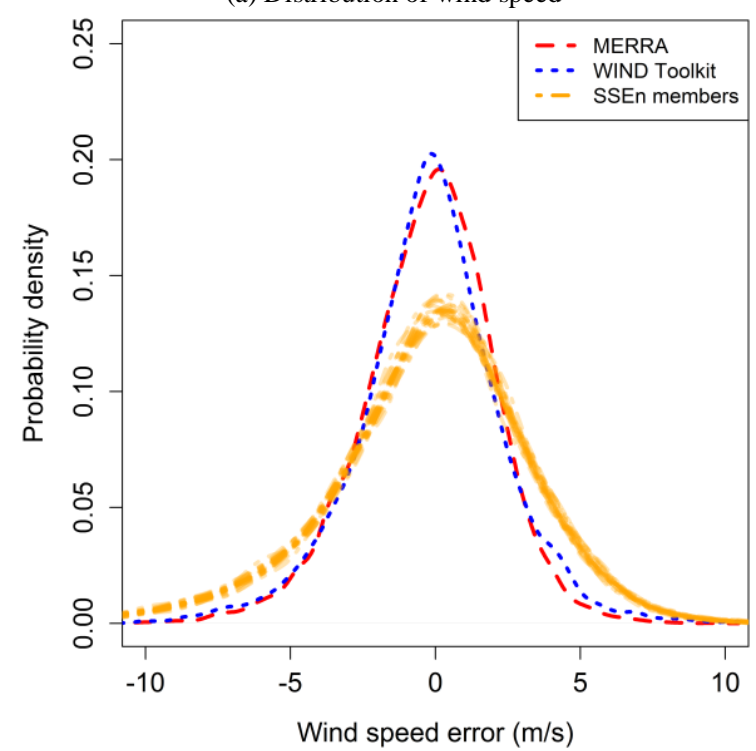

(c) Distribution of wind speed error

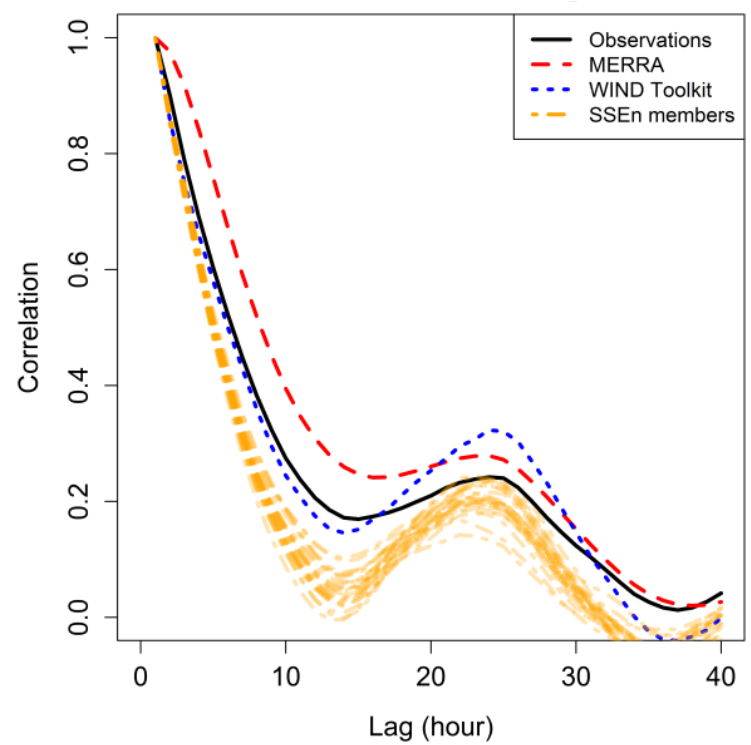

(b) Wind speed autocorrelation

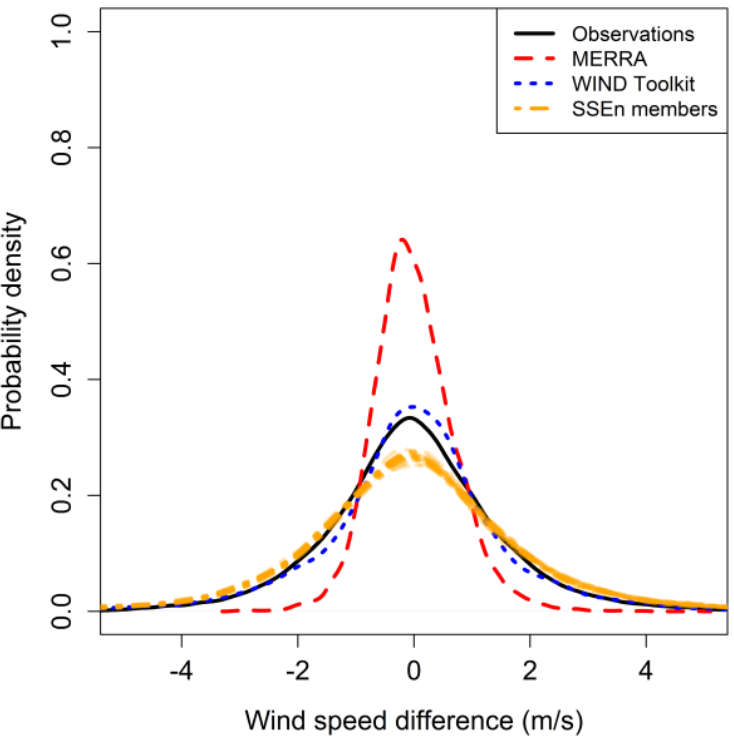

(d) Distribution of hourly wind speed differences 


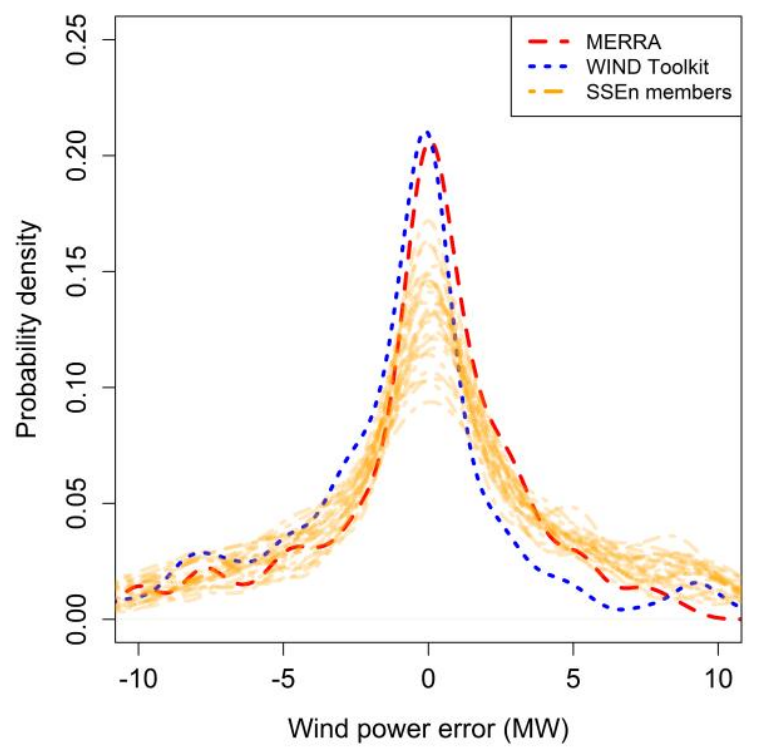

(e) Distribution of wind power error

Figure 5. Distribution of wind speed (a), autocorrelation of wind speed (b), distribution of wind speed error (c), hourly wind speed differences (d), wind power (e), and wind power error (f) for the observations and models as indicated by the legend at Bovina at $100 \mathrm{~m}$

Figure 6 shows the comparison results at the Cape May site. As for the Bovina site, both the WIND Toolkit and SSEn yield better results than MERRA, as expected. For the wind speed distribution (Fig. 6(a)), the SSEn is the closest to the observations, MERRA exhibit a low bias in the mode, and the WIND Toolkit underestimates the peak of the distribution. The WIND Toolkit demonstrates again its ability to catch the temporal variation (see wind speed autocorrelation in Fig. 6(b)), although SSEn is closer to the observations at this site than the previous site. Similar to the Bovina site, the SSEn members had fatter tails in the distribution of wind speed errors (Fig. 6(c)). The distribution of observed hourly wind speed differences (Fig. 6(d)) is best matched by SSEn and very closely by the WIND Toolkit. For the distributions of wind power errors in Fig. 6(e), MERRA exhibits a fat left tail while WIND Toolkit presents a relatively fat right tail; SSEn again has fatter tails than both MERRA and WIND Toolkit. A more detailed quantitative comparison among the distributions of wind speed and hourly wind speed differences is given in Section 5.4.

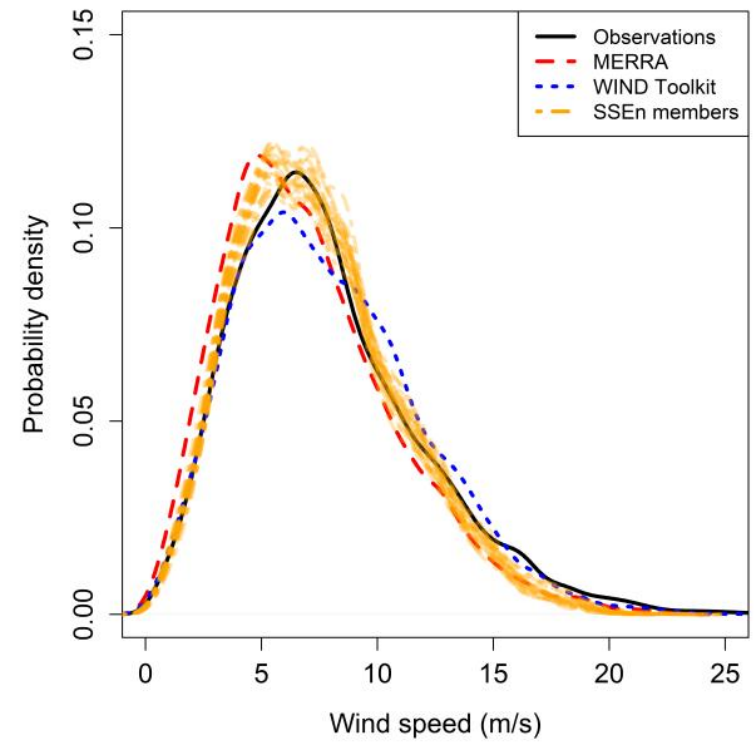

(a) Distribution of wind speed

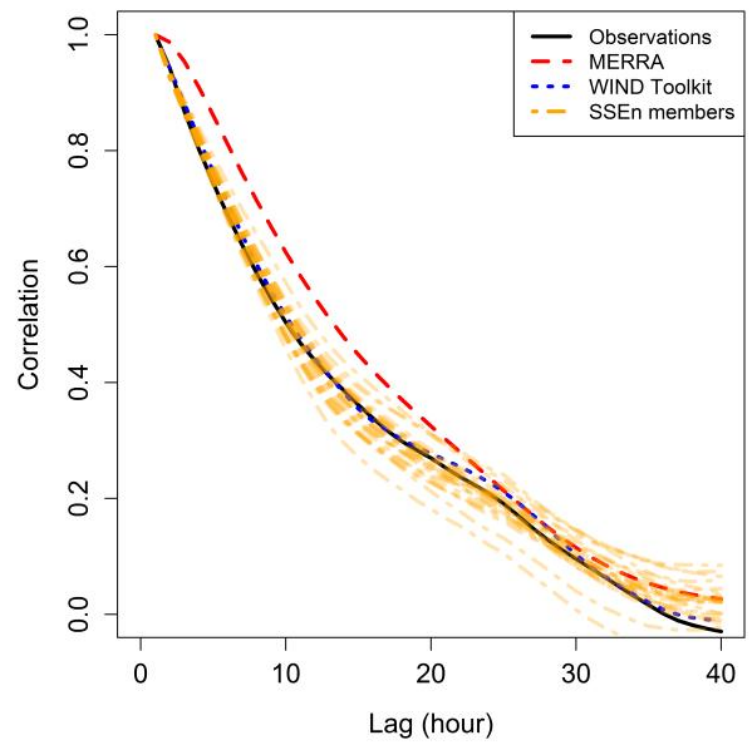

(b) Wind speed autocorrelation 


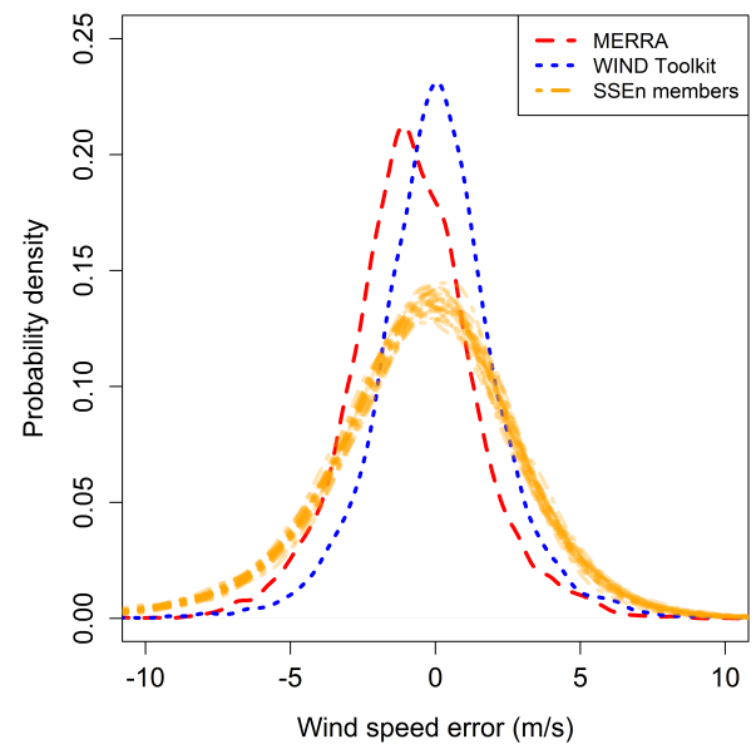

(c) Distribution of wind speed error

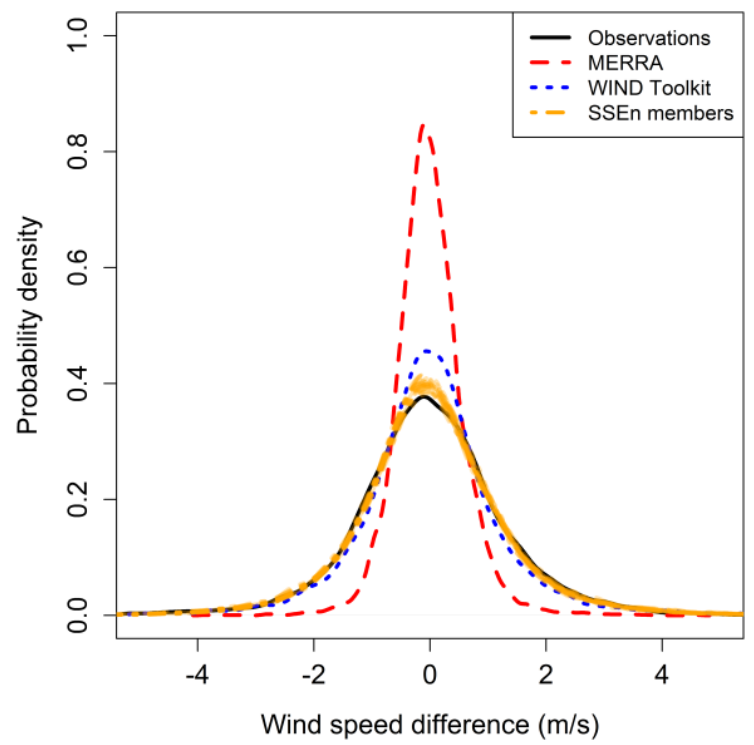

(d) Distribution of hourly wind speed differences

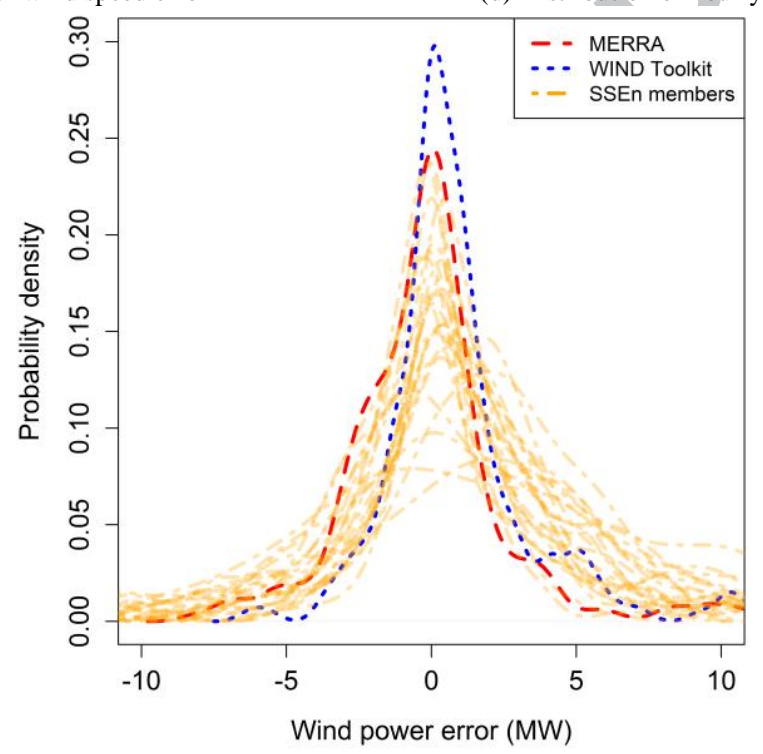

(e) Distribution of wind power error

Figure 6. Same as Figure 5, but for CapeMay site at $100 \mathrm{~m}$.

\subsection{Comparison at $80 \mathrm{~m}$-Boulder and Cedar Creek}

Figures 7 and 8 show the comparison results at Boulder and Cedar Creek, respectively, two sites with measured data at $80 \mathrm{~m}$. At the Boulder site, both the WIND Toolkit and SSEn outperform MERRA. Considering that the latter exhibits strong discrepancies from the observations at this site, it highlights the usefulness of both methods for complex terrain sites. Both the SSEn and the WIND Toolkit are in good agreement with the observations, with the SSEn having the most accurate distribution of wind speed (see Fig. 7(a)). The WIND Toolkit again performs the best at capturing the temporal characteristics (see Fig. 7(b)), although SSEn is better for lags above 20 hours. For the error distribution, the SSEn and the WIND Toolkit have a similar performance (Fig. 7(c)), while for the error differences distribution SSEn is closer to the observed differences (Fig. 7(d)). As shown in Fig. 7(e) for distribution of wind power errors, MERRA presents a large probability in the right tail, indicating an over-estimation trend in wind power generation. Both WIND Toolkit and SSEn provide a good estimation of wind power generation; and estimations from the 25 SSEn members are well distributed. 


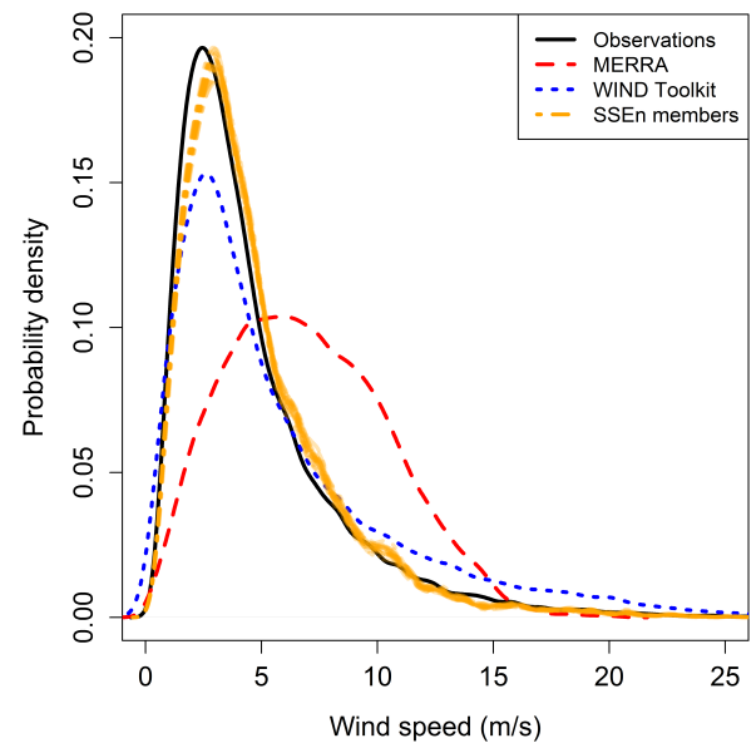

(a) Distribution of wind speed

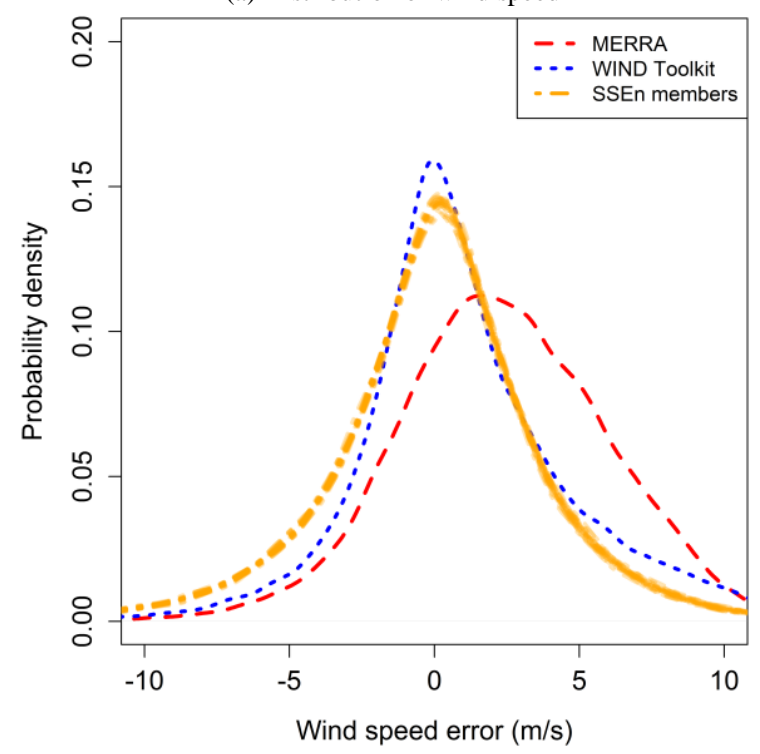

(c) Distribution of wind speed error

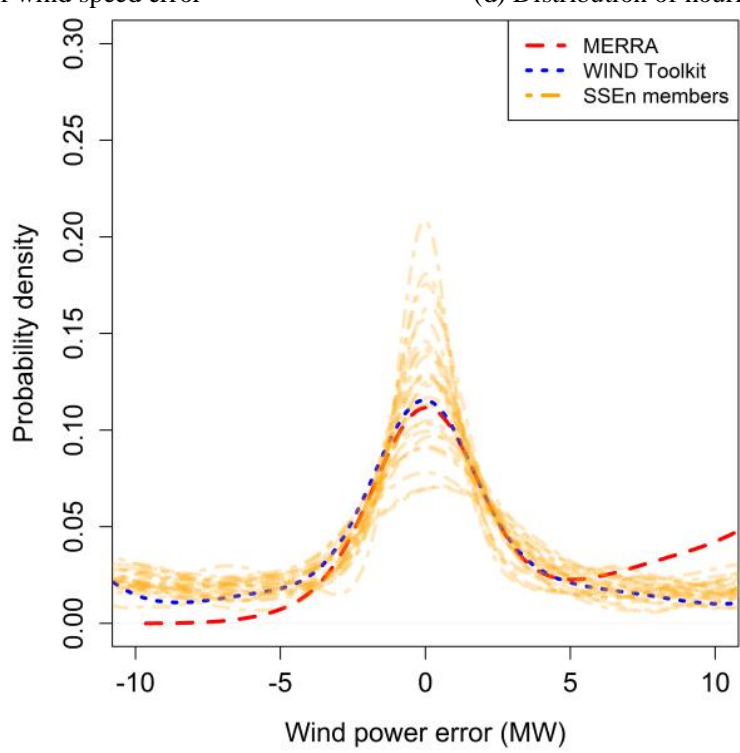

(e) Distribution of wind power error

Figure 7. Same as Fig. 5, but for Boulder NWTC at $80 \mathrm{~m}$.

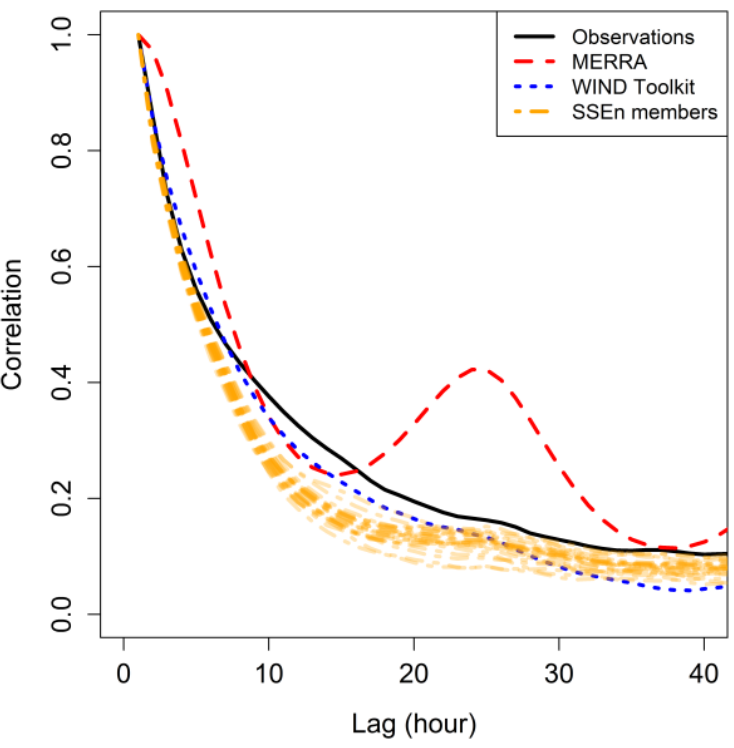

(b) Wind speed autocorrelation

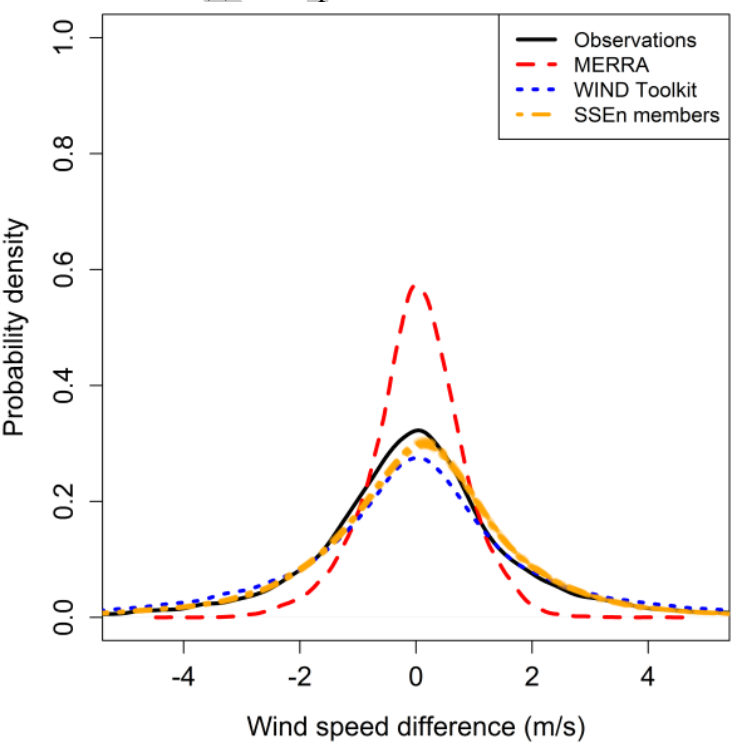

(d) Distribution of hourly wind speed differences 
For the site of Cedar Creek, the WIND Toolkit and SSEn have a similar estimate and outperform MERRA. Similarly to the Boulder site, the observed wind speed autocorrelation (Fig. 8(b)) is most closely matched by the WIND Toolkit than SSEn for the smaller lags (0-10 hours) and then by the SSEn for the larger lags (20-40 hours). For the distribution of wind speed errors (Fig. 8(c)), the SSEn has the fattest tails, indicating that the higher occurrence of larger wind speed errors with this method. The SSEn and WIND Toolkit characterize the wind variability more accurately (Fig. 8(d)), with SSEn being overall slightly better than the WIND Toolkit.

At both Boulder and Cedar Creek sites, which are characterized by topography considerably more complex than at Bovina or Cape May (Fig. 4), the SSEn advantage may come from the fact that its estimates are based on actual observations from the site, rather than the smoother model output as in the WIND Toolkit.

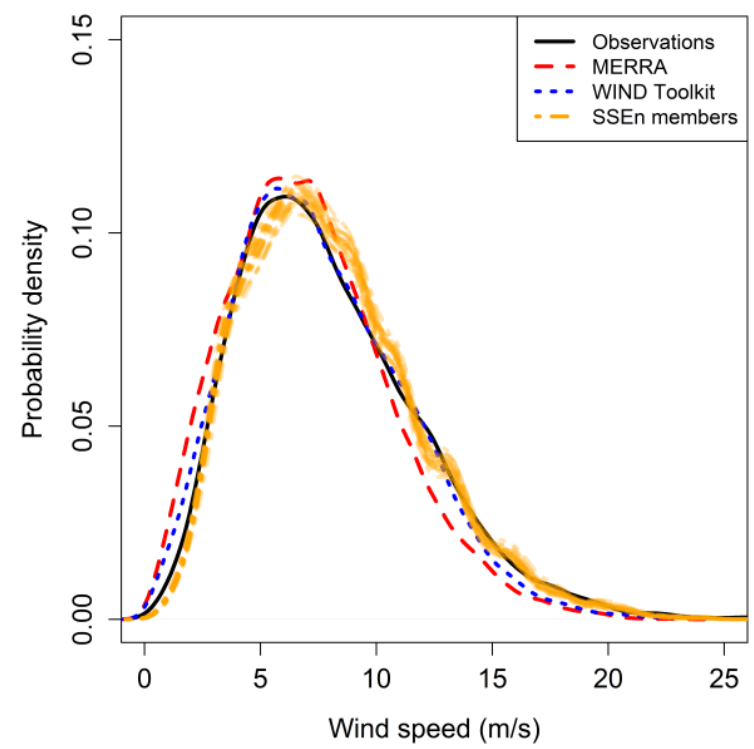

(a) Distribution of wind speed

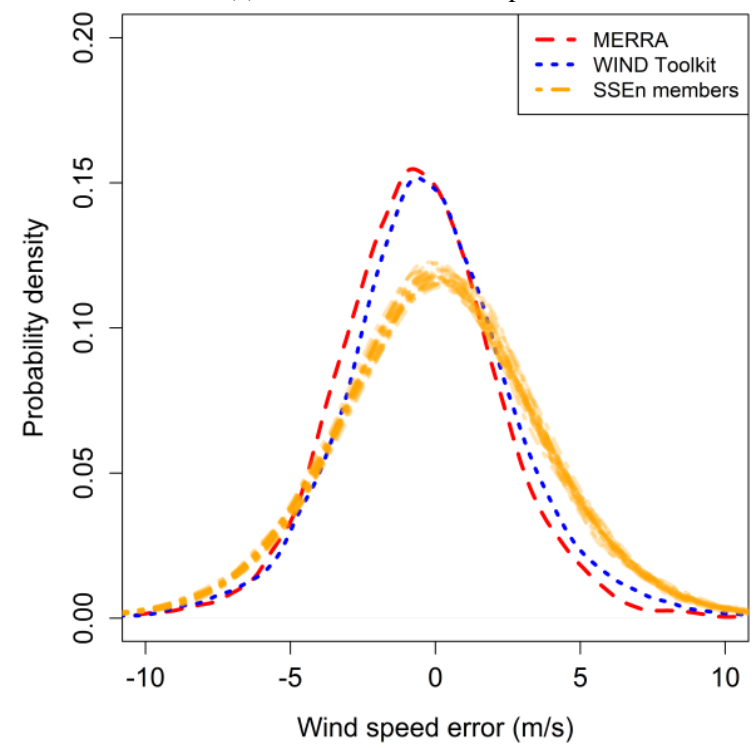

(c) Distribution of wind speed error

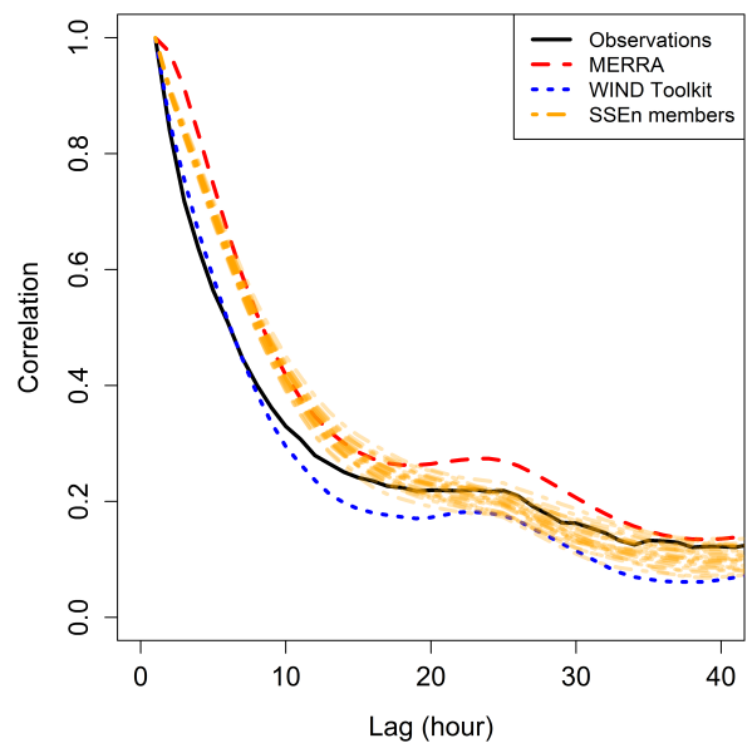

(b) Wind speed autocorrelation

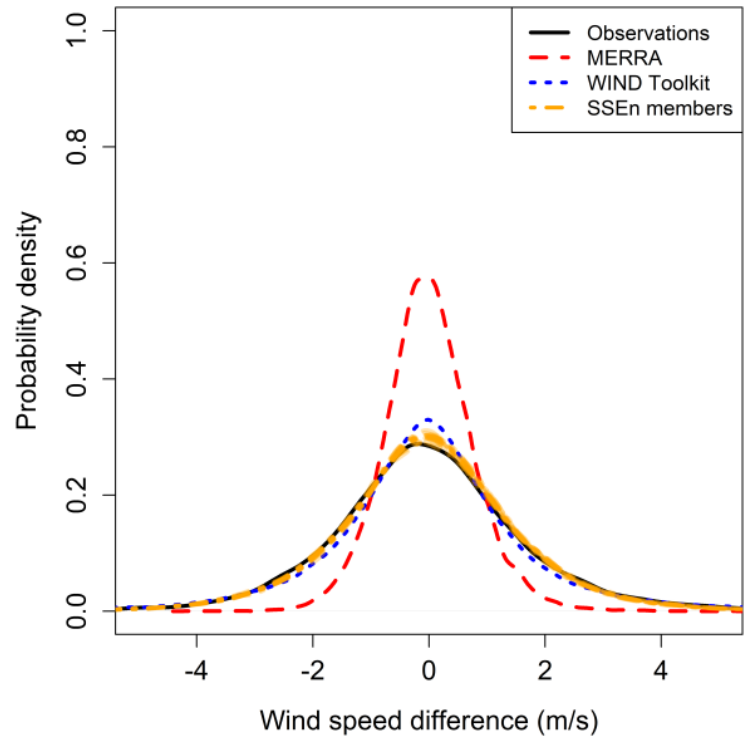

(d) Distribution of hourly wind speed differences 


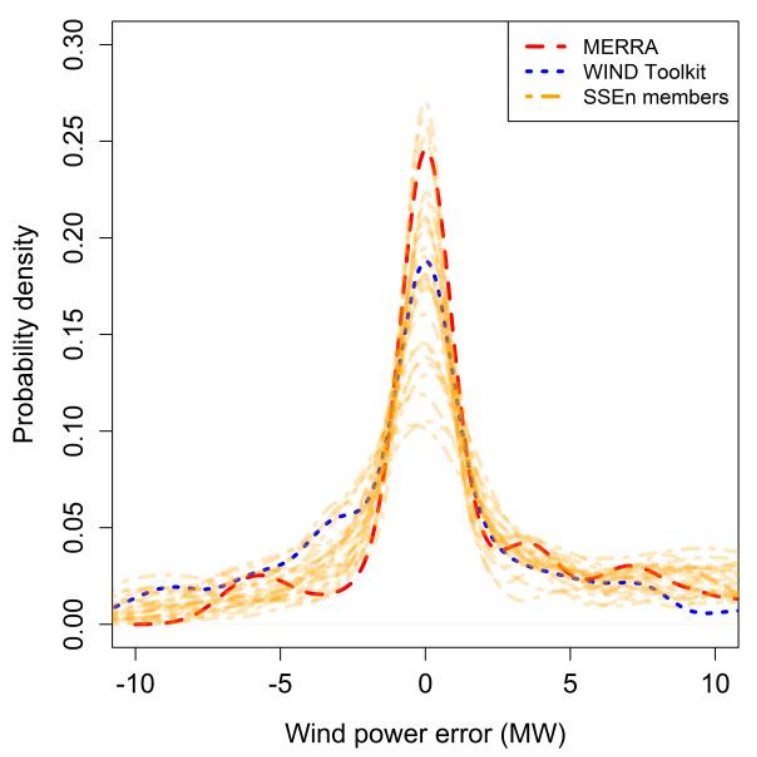

(e) Distribution of wind power error

Figure 8. Same as Fig. 5, but for Cedar Creek A09 at $80 \mathrm{~m}$.

\subsection{Comparison at Measured Heights Using the Wind Profile Power Law}

WIND Toolkit data is available at the heights of $10 \mathrm{~m}, 40 \mathrm{~m}, 60 \mathrm{~m}, 80 \mathrm{~m}, 100 \mathrm{~m}, 120 \mathrm{~m}, 140 \mathrm{~m}, 160 \mathrm{~m}$, and $200 \mathrm{~m}$. A portion of the errors and uncertainty of the WIND Toolkit derive from the fact that the WRF model levels, having a pressure dependency, vary their height above the ground in time and space. This requires a power law approximation [44] from the model levels to the desired fixed height of the observation. Moreover, a horizontal interpolation is necessary.

Assuming neutral atmospheric conditions, the mean wind speed in the surface layer is represented by the wind profile power law. For a known measured wind speed $U_{m}$ at a height $z_{m}$, the power law can be expressed as

$$
\frac{U}{U_{m}}=\left(\frac{z}{z_{m}}\right)^{\alpha}
$$

The exponent $\alpha$ is an empirically derived coefficient which is dependent upon the stability of the atmosphere. For neutral stability conditions, $\alpha$ is approximately $1 / 7$, which is adopted in this study.

\subsection{Quantitative comparison of wind speed distributions}

The Kullback-Leibler divergence is adopted to further compare the wind speed distributions to measure the difference between two probability distributions [45], i.e., the difference between the observed wind speed distribution and distribution of hourly wind speed differences, and the distributions fitted to the wind speed data predicted by the MERRA, the SSEn, and the WIND Toolkit. A smaller Kullback-Leibler divergence indicates a relatively more accurate distribution of predicted wind speeds.

Table 4 lists the Kullback-Leibler divergence between the observed and predicted wind speed distributions. For the SSEn, the distribution of wind speed is fitted using all data predicted by the 25 members. The smallest Kullback-Leibler divergence at each site is in bold. The SSEn produces a more accurate wind speed distribution at seven sites out of nine. The WIND Toolkit has a more accurate wind speed distribution at Cape May. The MERRA has a more accurate wind speed distribution at Bovina site with the $100 \mathrm{~m}$ data.

Table 4. Kullback-Leibler divergence between the actual and estimated distributions of wind speed.

\begin{tabular}{lccc}
\hline \multicolumn{1}{c}{ Station } & MERRA - Observation & All SSEn members - Observation & WIND Toolkit - Observation \\
\hline Bovina (100 m) & 0.016 & 0.017 & 0.018 \\
Cape May (100 m) & 0.023 & 0.038 & 0.008 \\
Boulder NWTC (80 m) & 0.348 & 0.011 & 0.064 \\
Cedar Creek (80 m) & 0.037 & 0.008 & 0.011 \\
Cochran (70 m) & 0.069 & 0.023 & 0.035 \\
Cedar Creek H06 (69 m) & 0.052 & 0.009 & 0.027 \\
Goodnoe Hills (59.4 m) & 0.130 & 0.008 & 0.086 \\
Megler (53.3 m) & 0.021 & 0.008 & 0.195 \\
\hline
\end{tabular}




\begin{tabular}{llll}
\hline Bovina $(50 \mathrm{~m})$ & 0.019 & 0.005 & 0.132 \\
\hline
\end{tabular}

Table 5 lists the Kullback-Leibler divergence between the actual and the predicted distributions of hourly wind speed differences. The results show that WIND Toolkit data is more accurate in estimating the distribution of hourly wind speed differences at five sites out of nine, whereas SSEn is the most accurate at the four remaining sites. At Bovina at $100 \mathrm{~m}$, the WIND Toolkit has the smallest Kullback-Leibler divergence; however, the SSEn has a slightly smaller Kullback-Leibler divergence than the WIND Toolkit at $50 \mathrm{~m}$. This may be attributed at least in part to additional WIND Toolkit errors introduced by the interpolation and the power law approximation, which are necessary steps when dealing with NWP-based estimates. The distribution of hourly wind speed difference is a metric to quantify the variability of wind power. The level of the wind variability plays a critical role in the grid integration of wind energy. Generally, the wind power with less variability is easier and cheaper to be integrated in power systems.

\begin{tabular}{lccc} 
Table 5. Kullback-Leibler divergence between the actual distribution and the estimated distributions of hourly wind speed differences \\
\cline { 2 - 3 } \multicolumn{1}{c}{ Station } & MERRA - Observation & All SSEn members - Observation & WIND Toolkit - Observation \\
\hline Bovina (100 m) & 0.269 & 0.018 & 0.004 \\
Cape May (100 m) & 0.267 & 0.021 & 0.015 \\
Boulder NWTC (80 m) & 0.200 & 0.005 & 0.016 \\
Cedar Creek (80 m) & 0.271 & 0.002 & 0.006 \\
Cochran (70 m) & 0.137 & 0.016 & 0.013 \\
Cedar Creek H06 (69 m) & 0.255 & 0.001 & 0.004 \\
Goodnoe Hills (59.4 m) & 0.433 & 0.073 & 0.010 \\
Megler (53.3 m) & 0.467 & 0.013 & 0.007 \\
Bovina (50 m) & 0.310 & 0.003 & 0.024 \\
\hline
\end{tabular}

\section{Discussion}

The analog-based method is capable of providing both deterministic and probabilistic wind resource estimates. The analog ensemble was generated only based on one deterministic low-resolution NWP model based estimate (MERRA), which considerably reduced the computational cost of generating an ensemble. Both the Schaake Shuffle Ensemble (SSEn) and WIND Toolkit provided more accurate assessment than the MERRA data. Also, the SSEn seems to perform better than the WIND Toolkit at locations characterized by complex topography, an advantage that may come from the fact that its estimates are based on actual observations from the site, rather than the smoother WRF output as in the WIND Toolkit.

While observational data is to be favored when using the analog-based method, it cannot be available for all locations considered for future high wind penetration scenarios. The use of reanalysis datasets removes the need for observational data. Using mesoscale dynamical models has the advantage of being able to simulate a large number of locations while estimating the covariance structure of the spatial fields, which is essential for integration studies [46]. Over the nine locations considered in this study, the SSEn method is better at estimating the wind distribution at seven locations, whereas the distribution of hourly wind speed differences is best estimated by the WIND Toolkit at five locations. The WIND Toolkit provides a freely available wind speed and power data set that can be used for wind resource assessments, as well as grid integration and grid planning studies. It will allow users to perform detailed simulations of how the future power system will operate under high penetration scenarios.

The MERRA data set could be used for preliminary analysis of wind resource assessment. In conjunction with the measured data from the wind sites, an analog ensemble method can be used for a more comprehensive and accurate wind resource assessment. Thus, the analog ensemble methods, particularly the SSEn, are more suitable for wind speed estimations at a single wind site (or a small number of wind sites) with available measured short-term wind data. It is also important to note that, while the SSEn had a smaller Kullback-Leibler divergence than the WIND Toolkit at most wind sites, the SSEn present a fatter tail than the WIND toolkit in terms of the distribution of wind speed errors. The WIND Toolkit data set is publicly available and covers the continental United States for the 7 years, which is more suitable for wind resource assessment and wind grid integration studies for a large area.

Future efforts could focus on combining the analog ensemble with high-resolution NWP based methods as the WIND Toolkit, with the goal of making the best use of the available computational resources while providing accurate estimates and reliable uncertainty quantification. For instance, the WRF model could be run at a coarser resolution (e.g., 10-15 km) than the actual WIND Toolkit, but for a longer period of time (e.g., 20 years), and then downscaled with the analog ensemble similarly to the application of the latter to the MERRA, which was presented in this study. 


\section{Conclusion}

This paper compared three numerical weather prediction (NWP) based methods for wind resource assessment and wind integration. The methods are: (i) a low resolution NWP data set, the Modern-Era Retrospective Analysis for Research and Applications (MERRA); (ii) an analog ensemble methodology based on the MERRA reanalysis which provides both deterministic and probabilistic predictions; and (iii) a high resolution NWP data set, the Wind Integration National Dataset (WIND) Toolkit, based on the Weather Research and Forecasting model. The comparison of three methods was tested at 9 locations across the United States. Two sets of performance metrics were adopted: (i) wind speed metrics, including distribution of wind speed, temporal autocorrelation of wind speed, distribution of wind speed error, and distribution of hourly wind speed difference; and (ii) wind farm performance: power generation of a hypothetical nine-turbine wind farm.

Comparison and analysis results showed that: (i) as expected, the analog ensemble and WIND Toolkit perform significantly better than MERRA confirming their ability to downscale coarse estimates; (ii) the analog ensemble provides the best estimate of the multi-year wind distribution at seven of the nine sites available, with the WIND Toolkit being the best at one site; and (iii) the WIND Toolkit was more accurate in estimating the distribution of hourly wind speed differences which characterize the wind variability at five of the available sites, with the analog ensemble being best at the remaining four locations.

\section{Acknowledgements}

This work was supported by the U.S. Department of Energy under Contract No. DE-AC36-08-GO28308 with the National Renewable Energy Laboratory.

\section{References}

[1] WWEA, World wind energy report 2013, Technical Report, World Wind Energy Association, Bonn, Germany, April 2014.

[2] Drunsic M. Accurate wind assessments: pinning down performance. 2012 (last accessed: July 2013), http://www.renewableenergyworld. com/rea/news/article/2012/06/accurate-wind-assessments-pinning-downperformance.

[3] Rodrigo JS. State-of-the-art of wind resource assessments. Waudit Deliv D7. CENER National Renewable Energy Centre; 2010.

[4] NYSERDA. Wind resource assessment handbook, New York state energy research and development authority, final report 10-30. 2010.

[5] DNV KEMA \& Second Wind. Reducing uncertainty in wind project energy estimates: a cost-benefit analysis of additional measurement campaign methods, white paper. 2012.

[6] Velazquez S, Carta JA, Matias JM. Comparison between anns and linear mcp algorithms in the long-term estimation of the cost per kwh produced by a wind turbine at a candidate site: a case study in the canary islands. Applied Energy 2011; 88(11):3689-881.

[7] Rogers AL, Rogers JW, Manwell JF. Comparison of the performance of four measure-correlate-predict algorithms. Journal of Wind Engineering and Industrial Aerodynamics 2005; 93(3): 43-64.

[8] Carta JA, Velazquez S, Cabrera P. A review of measure-correlate-predict (MCP) methods used to estimate long-term wind characteristics at a target site. Applied Energy 2013;27:362-400.

[9] Zhang J, Chowdhury S, Messac A, Hodge BM. A hybrid measure-correlate-predict method for long-term wind condition assessment. Energy Conversion and Management 2014; 87:697-710.

[10] Al-Yahyai S, Charabi Y, Gastli A. Review of the use of Numerical Weather Prediction (NWP) Models for wind energy assessment. Renewable and Sustainable Energy Reviews 2010;14:3192-3198.

[11] Jimenez B, Durante F, Lange B, Kreutzer T, Tambke J. Offshore wind resource assessment with WAps and MM5: comparative study for the German Bight. Wind Energy 2007; 10:121-134.

[12] Chagas GO, Guedes RA, Manso MDO. Estimating wind resource using mesoscale modeling. European Wind Energy Conference (EWEC); 2009.

[13] Cassola F, Burlando, M. Wind speed and wind energy forecast through Kalman filtering of Numerical Weather Prediction model output. Applied Energy 2012; 99:154-166.

[14] Alessandrini S, Sperati S., Sperati, P. A comparison between the ECMWF and COSMO Ensemble Prediction Systems applied to short-term wind power forecasting on real data. Applied Energy 2013; 107:271-280.

[15] Carvalho D, Rocha A, Gómez-Gesteira M, Santos CS. WRF wind simulation and wind energy production estimates forced by different reanalyses: Comparison with observed data for Portugal. Applied Energy 2014; 117:116-126.

[16] Carvalho D, Rocha A, Gómez-Gesteira M, Santos CS. Sensitivity of the WRF model wind simulation and wind energy production estimates to planetary boundary layer parameterizations for onshore and offshore areas in the Iberian Peninsula. Applied Energy 2014; 135:234-246.

[17] Elliott DL, Holladay CG, Barchet WR, Foote HP, Sandusky WF. Wind energy resource atlas of the United States. Solar technical information program. Golden, Colorado: National Renewable Energy Laboratory, http://rredc.nrel.gov/wind/pubs/atlas; 1986.

[18] Lew D, et al. The western wind and solar integration study. Technical Rep. NREL/SR-550-47434, National Renewable Energy Laboratory, Golden, CO, 2010.

[19] Lew D, et al. The western wind and solar integration study phase 2. Technical Rep. NREL/TP-5500-55888, National Renewable Energy Laboratory, Golden, CO, 2013.

[20] Corbus D, et al. Eastern wind integration and transmission study. Technical Rep. NREL/SR-5500-47086, National Renewable Energy Laboratory, Golden, CO, 2011.

[21] Rienecker MM, Suarez MJ, Gelaro R, Todling R, Bacmeister J, Liu E, Bosilovich MG, Schubert SD, Takacs L, Kim GK. MERRA: NASA's modern-era retrospective analysis for research and applications. Journal of Climate 2011; 24:3624-3648. 
[22] Vanvyve E, Delle Monache L, Monaghan AJ, Pinto JO. Wind resource estimates with an analog ensemble approach. Renewable Energy 2015; 74:761-773.

[23] Draxl C, Hodge BM, Clifon A, McCaa J. Overview and Meteorological Validation of the Wind Integration National Dataset (WIND) Toolkit. tech. rep. NREL/TP-5000-61740. Golden, CO: National Renewable Energy Laboratory.

[24] King J, Clifton A., Hodge, BM. Validation of Power Output for the WIND Toolkit. Technical Rep. NREL/TP-5D00-61714, National Renewable Energy Laboratory, Golden, CO, 2014.

[25] Hopson, T, Webster, P. A 1-10-Day Ensemble Forecasting Scheme for the Major River Basins of Bangladesh: Forecasting Severe Floods of 2003-07. Journal of Hydrometeorology 2010; 11:618-641.

[26] Hamill TM, Whitaker JS. Probabilistic quantitative forecasts based on reforecast analogs: theory and application. Monthly Weather Review 2006; 134:3209-3229.

[27] Delle Monache L, Nipen T, Liu Y, Roux G, Stull R. Kalman filter and analog schemes to postprocess numerical weather predictions. Monthly Weather Review 2011; 139:3554-3569.

[28] Delle Monache L, Eckel FA, Rife DL, Nagarajan B, Searight K. Probabilistic weather prediction with an analog ensemble. Monthly Weather Review 2013; 141:3498-3516.

[29] Alessandrini S, Davò F, Sperati S, Benini M, Delle Monache L. Comparison of the economic impact of different wind power forecast systems for producers. Advances in Science and Research 2014; 11:49-53.

[30] Nagarajan B, Delle Monache L, Hacker J, Rife D, Searight K, Knievel J, Nipen T. An evaluation of analog-based post-processing methods across several variables and forecast models. Weather and Forecasting 2015. (Accepted)

[31] Junk, C, Delle Monache L, Alesandrini S, Cervone G, von Bremen L. Predictor-weighting strategies for probabilistic wind power forecasting with an analog ensemble. Meteorologische Zeitschrift 2015 (Accepted).

[32] Clark M, Gangopadhyay S, Hay L, Rajagopalan B, Wilby R. The Schaake Shuffle: A Method for Reconstructing Space-Time Variability in Forecasted Precipitation and Temperature Fields. Journal of Hydrometeorology 2004; 5:243-262.

[33] Skamarock W, Klemp J, Dudhia J, Gill D, Barker D, Duda M, Huang XY, Wang W, Powers J. A Description of the Advanced Research WRF Version 3. National Center for Atmospheric Research 2008; Boulder, CO (USA).

[34] Draxl C, Clifton A, Hodge, B, McCaa, J. The Wind Integration National Dataset (WIND) Toolkit. Applied Energy 2015; 151:355366.

[35] Windographer, http://www.windographer.com, last accessed May 2014.

[36] Zhang J, Chowdhury S, Messac A, Castillo L. A multivariate and multimodal wind distribution model. Renewable Energy 2013; $51: 436-447$.

[37] Zhang J, Hodge B, Florita A. Joint Probability Distribution and Correlation Analysis of Wind and Solar Power Forecast Errors in the Western Interconnection. Journal of Energy Engineering 2015; 141:B4014008.

[38] Juban J, Siebert N, Kariniotakis GN. Probabilistic short-term wind power forecasting for the optimal management of wind generation. IEEE Power Eng. Society, Lausanne Power Tech Conf. Proc., 2007: 683-688.

[39] Chowdhury S, Zhang J, Messac A, Castillo L. Unrestricted Wind Farm Layout Optimization (UWFLO): Investigating Key Factors Influencing the Maximum Power Generation. Renewable Energy 2012; 38(1):16-30.

[40] Chowdhury S, Zhang J, Messac A, Castillo L. Optimizing the Arrangement and the Selection of Turbines for Wind Farms Subject to Varying Wind Conditions. Renewable Energy 2013; 52:273-82.

[41] Frandsen S, Barthelmie R, Pryor S, Rathmann O, Larsen S, Hojstrup J, hogersen M. Analytical modeling of wind speed deficit in large wind offshore wind farms. Wind Energy 2006; 9(1-2):39-53.

[42] Katic I, Hojstrup J, Jensen NO. A simple model for cluster efficiency. Proceedings of European Wind Energy Conference and Exhibition, Rome (Italy); 1986.

[43] GE, GE Energy 1.5MW Wind Turbine Brochure, General Electric, http://www.gepower.com/, 2010.

[44] Stull RB. An Introduction to Boundary Layer Meteorology, Springer; July 1998.

[45] Kullback, S, Leibler, RA. On information and sufficiency. The Annals of Mathematical Statistics 1951; 22(1):79-86.

[46] Lew D, Alonge C, Brower M, Frank J, Freeman L, Orwig K, Potter C, Wan YH. Wind Data Inputs for Regional Wind Integration Studies. IEEE Power \& Energy Society Annual Meeting, Detroit, MI, 2011. 